Data Repository for: Evolution of a natural debris flow: in situ measurements of flow dynamics, video imagery, and terrestrial laser scanning Scott W. McCoy ${ }^{1}$, Jason W. Kean ${ }^{2}$, Jeffrey A. Coe ${ }^{2}$, Dennis M. Staley ${ }^{2}$, Thad A. Wasklewicz $^{3}$, and Gregory E. Tucker ${ }^{1}$

\title{
Sensor Specifications
}

The cross section at the upper station in the west channel includes instruments to measure stage, basal pore-fluid pressure, total basal normal stress, rainfall and temperature. A video camera, located across the valley, captures video imagery of the reach immediately above and below the upper station. The instrumented cross section at the middle station has the same sensors as the upper station minus the force plate. The video camera filming the middle station turned off before the flow could be recorded.

The ultrasonic stage sensor, rain gauge, temperature probe and data logger were installed on an aluminum bridge that spans the channel (DR1 D). During the installation of the force plate there was approximately 0.5 meters of loose sediment in the bedrock channel. This sediment was shoveled aside to expose the bedrock channel bed. Using a rock saw, hammer and chisel a $20 \mathrm{~cm}$ by $20 \mathrm{~cm}$ by $20 \mathrm{~cm}$ hole was dug into the bedrock. The force plate was placed in the hole and all remaining space was filled with anchoring cement. Pressure transducers were placed inside 2.5 $\mathrm{cm}$ diameter steel conduit and pressed into the wet anchoring cement along side the force plate. Care was taken to insure that the transducer ends remained open (DR1 E). Once the installation was finished, the loose channel sediment was put back in place and the sediment bed was restored to the pre-installation condition.

Sensor specifications, as provided by the manufacturer or found on recent calibration certification sheets, are reproduced below.

\section{Data logger}

Model: Campbell Scientific CR1000

\section{Ultrasonic Stage sensor}

Model: Campbell Scientific SR50A-L Sonic ranging sensor

Accuracy: $+/-1.0 \mathrm{~cm}$

Sample frequency: $0.5 \mathrm{~Hz}$

Beam angle: 30 degrees. This results in $\sim 1 \mathrm{~m}$ diameter sampling area when distance to target is 2 m.

Sensitivity to temperature: The travel time of the ultrasonic pulse, which is used to determine the distance to the target, is sensitive to the air temperature. This dependency is corrected using $D_{\text {corrected }}=D_{\text {measured }} \sqrt{T / 273.15}$ where $D_{\text {corrected }}$ is the temperature corrected distance to target, $D_{\text {measured }}$ is the distance measured using the speed of sound at $0^{\circ} \mathrm{C}(331.4 \mathrm{~m} / \mathrm{s})$ and $T$ is the current temperature in ${ }^{\circ}$ Kelvin.

Comments: In addition to measuring the distance to the target the sensor reports quality numbers that measure the certainty of the distance measurement. The quality numbers range from 152600 , where $152-210$ is good quality, 210-300 is reduced echo signal strength and 300-600 is high uncertainty. As a post-processing step we only used distance measurements with quality numbers between 152-210. 


\section{Single-axis force transducer (sensor inside custom force plate enclosure)}

Model: Tovey Engineering SWS10

Accuracy (static error band): $+/-2.5 \mathrm{~kg}, 25 \mathrm{~N}$

Accuracy (nonrepeatability): $+/-0.5 \mathrm{~kg}, 5 \mathrm{~N}$

Maximum load: $4500 \mathrm{~kg}, 45,000 \mathrm{~N}$

Sample Frequency: $250 \mathrm{~Hz}$

Area of measurement plate: $0.0232 \mathrm{~m}^{2}$

Sensitivity to temperature:

Effect on zero: $+/-7 \mathrm{~kg}$ per $100{ }^{\circ} \mathrm{C}, 70 \mathrm{~N}$ per $100{ }^{\circ} \mathrm{C}$

Effect on sensitivity: $+/-4 \mathrm{~kg}$ per $100^{\circ} \mathrm{C}, 40 \mathrm{~N}$ per $100{ }^{\circ} \mathrm{C}$

\section{Pressure transducer}

Model: Solinst Levelogger M3001 F15/M5 (silicon piezoresitive transducer) Accuracy: +/- $0.003 \mathrm{~m}$ water pressure head, $+/-0.03 \mathrm{kPa}$

Maximum load: $5 \mathrm{~m}$ water pressure head, $50 \mathrm{kPa}$

Sample Frequency: $0.5 \mathrm{~Hz}$

Area of measurement plate: $0.00152 \mathrm{~m}^{2}$

Sensitivity to temperature: Automatic internal temperature compensation using internal temperature probe results in stable output.

\section{Rain gauge}

Model: Hydrological Services TB4 siphoning tipping bucket rain gauge

Accuracy: $+/-2 \%$ for intensities from $25-500 \mathrm{~mm} / \mathrm{hr}$

Range: $0-700 \mathrm{~mm} / \mathrm{hr}$

Receiver diameter: $0.20 \mathrm{~m}$

\section{Video Camera and Still Camera}

Model: Erdman Video Systems, Inc. "Mini Biscuit"

Video: Sony Block Camera Model FCB-EX480A

Frame Rate: 2 frames per second

Resolution: 640 X 480 pixels

Still: Olympus SP500-6Megapixel Camera

Frame Rate: 1 picture every 30 seconds

Resolution: 1536 X 2048 pixels

\section{Terrestrial Laser Scanning Specifications}

Instrument: Leica Geosystems HDS ScanStation 2

Instrument Type: Pulsed, dual-axis compensated, very-high speed laser scanner, with surveygrade accuracy, range, and field-of-view

User Interface: Dell XFR D630 Ruggedized Notebook

Scanner Drive: Servo motor - motor is direct drive, brushless

Camera: Integrated high-resolution digital camera

Single Measurement Accuracy: Position $=6 \mathrm{~mm}$, distance $=4 \mathrm{~mm}$, angle $($ horizontal $/ \mathrm{vertical})=$ 
$60 \mu \mathrm{rad} / 60 \mu \mathrm{rad}$, one sigma

Dual-axis Compensator: On

Laser Class: 3R (IEC 60825-1)

Range: 300 m@90\%; 134 m@18\% albedo

Scan Rate: Up to 50,000 points/sec, maximum instantaneous rate - average: dependent on specific scan density and field-of-view

Spot Size: From 0 - 50m:4mm (FWHH - based); 6mm (Gaussian - based)

Point Spacing: Fully selectable horizontal and vertical; $<1 \mathrm{~mm}$ minimum spacing, through full

Field-of-view (per scan): Horizontal $360^{\circ}$ (maximum) and Vertical $270^{\circ}$ (maximum)

Scanning Optics: Single mirror, panoramic, front and upper window design

Communications: Static Internet Protocol (IP) Address

Power supply: $36 \mathrm{~V}$; AC or DC; hot swappable

Power Consumption: $<80 \mathrm{~W}$ avg.

Lighting: Fully operational between bright sunlight and complete darkness 


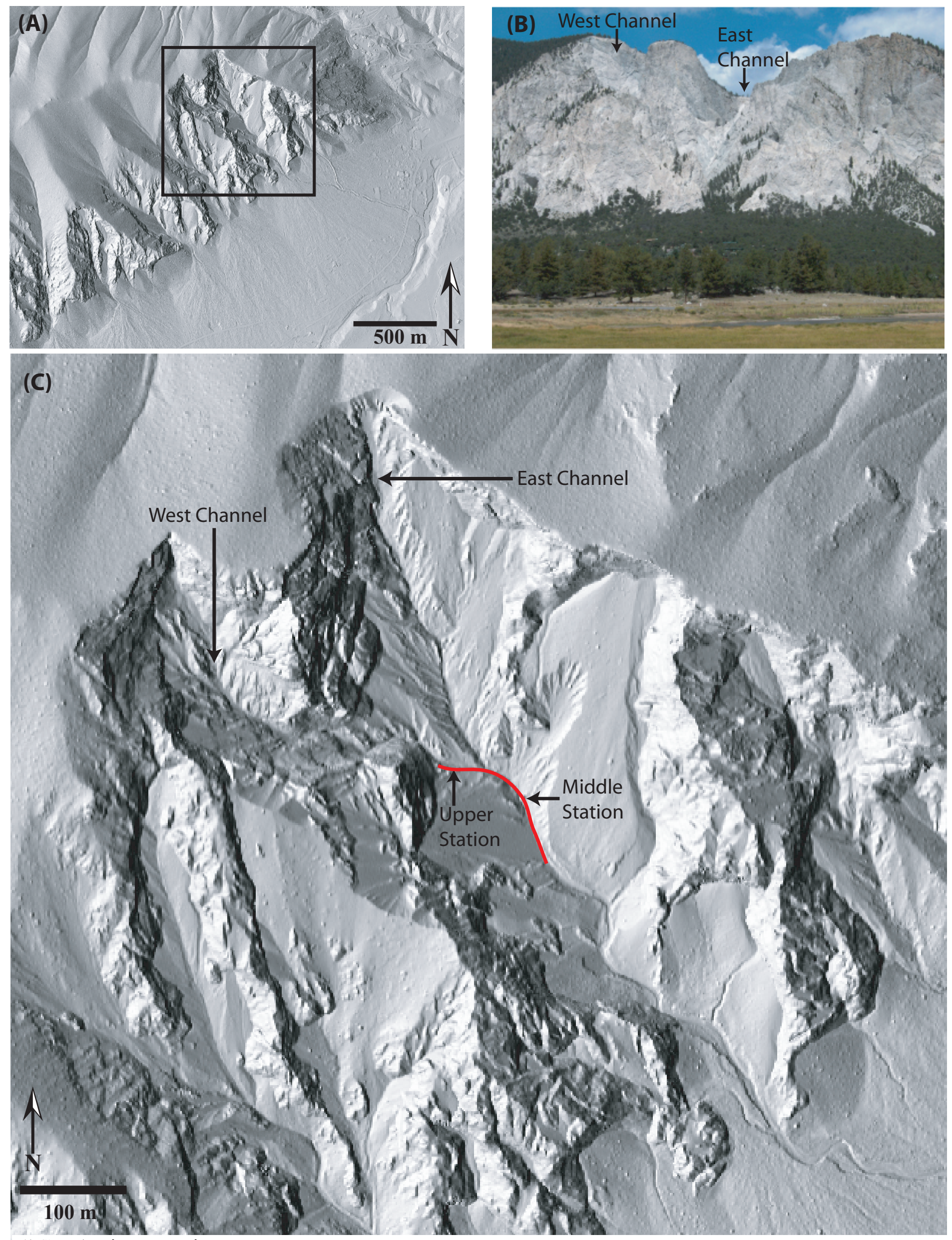

) IJUDR1. Figure caption on next page. 

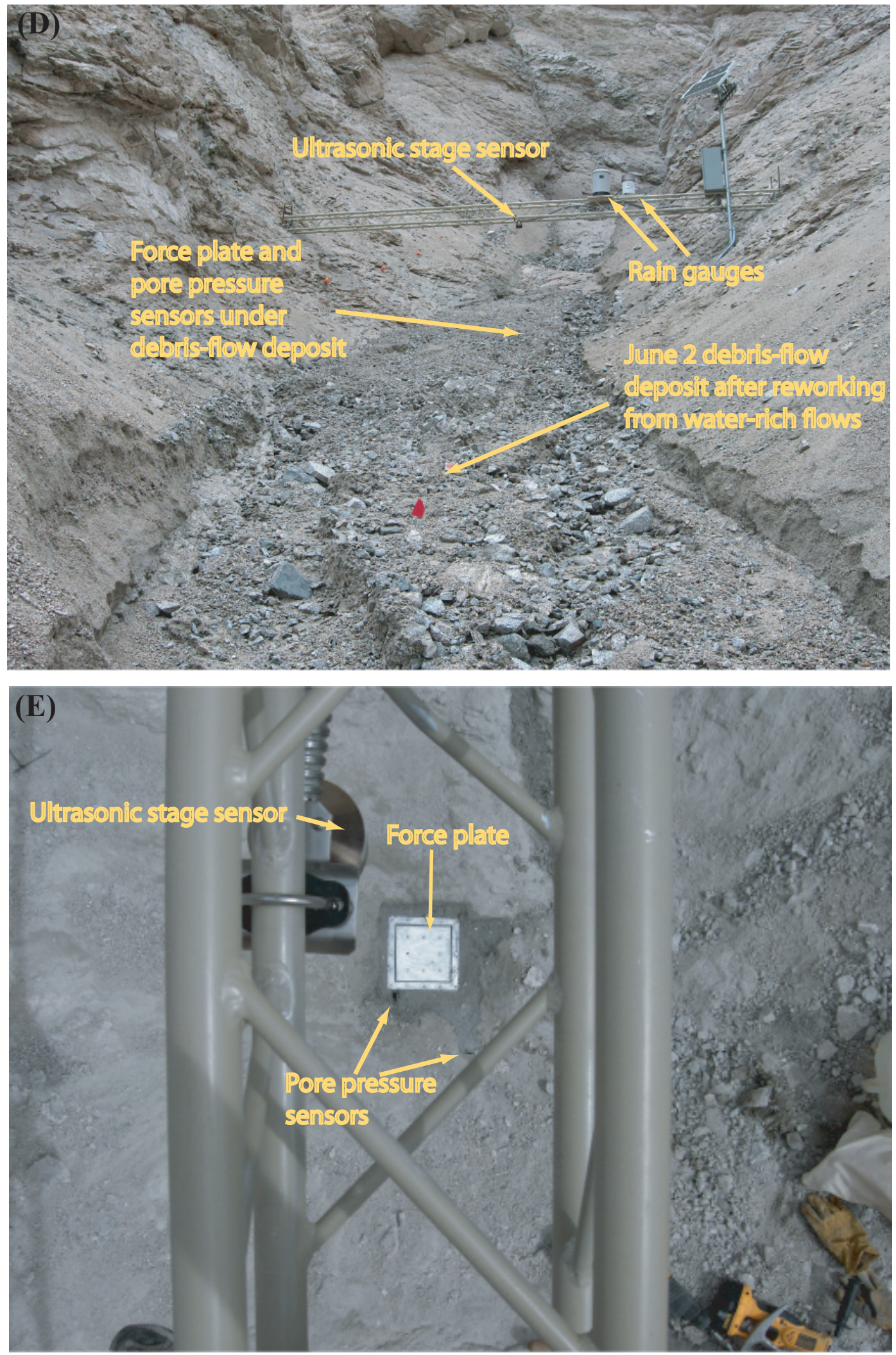

) IJWDR1. A: Bare-earth hillshade from $1 \mathrm{~m}$ ALSM data of the Chalk Cliffs area. ALSM data provided by NCALM. Black box delimits study area shown in C. B: Land-based photograph, view to the north-northwest, showing the forest-covered fan and predominately bedrock upper basin. Top of west channel is at an elevation of $3100 \mathrm{~m}$, downslope most elevation of fan is $2500 \mathrm{~m}$. C: Upper basin of Chalk Cliffs. Red line indicates channel length surveyed with TLS. D: Upper station, bridge is $6.1 \mathrm{~m}$ long. E: View from above, looking through the bridge at sensors mounted in bedrock at the upper station, with loose channel sediment pushed aside. 


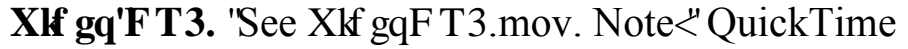

Player of version 7 or higher is required to play the video. Video of multiple surges passing the upper station. The bridge spanning the channel is $6.1 \mathrm{~m}$ long. The larger rain gauge on the bridge is $0.33 \mathrm{~m}$ tall. 


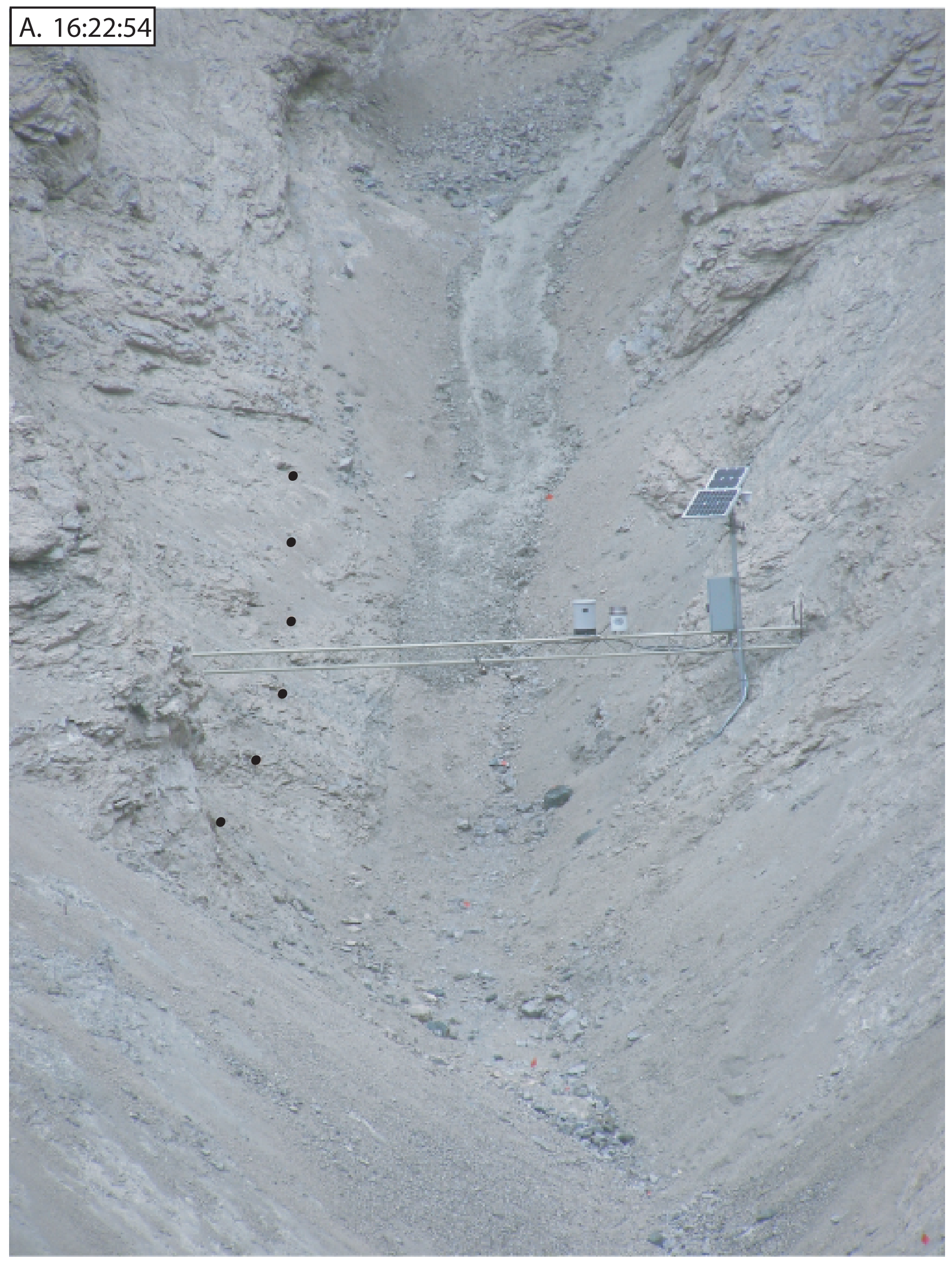

) IJ $\square$ DR3. A-D: High-resolution photograph of debris-flow surge taken at the upper station. Black dots are spaced $2 \mathrm{~m}$ apart. Larger rain gauge is $0.33 \mathrm{~m}$ tall. Note the differences between the steep surge front of coarse-grained material without interstitial fluid visible at the surface and the water-rich tail that follows. 


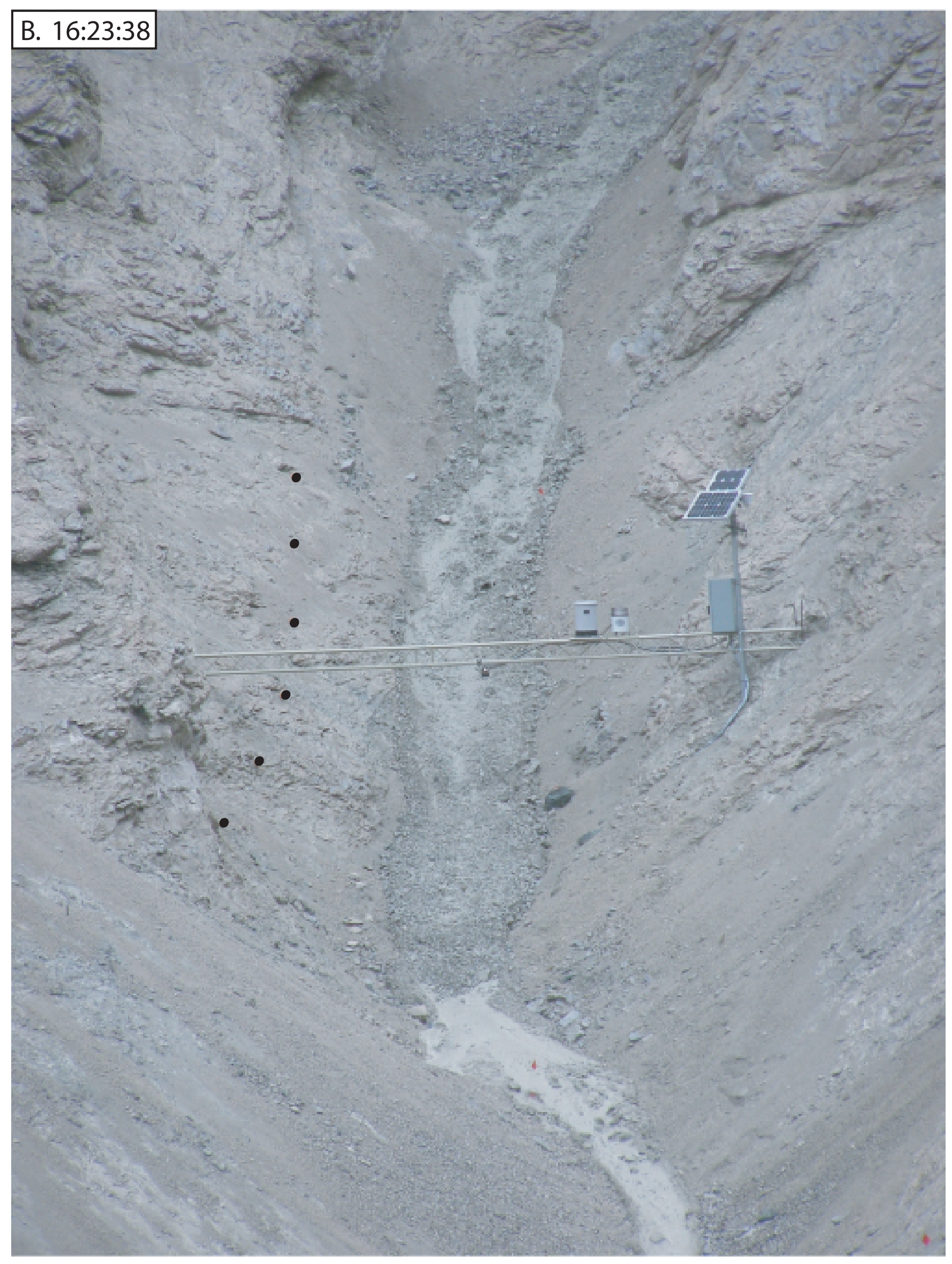




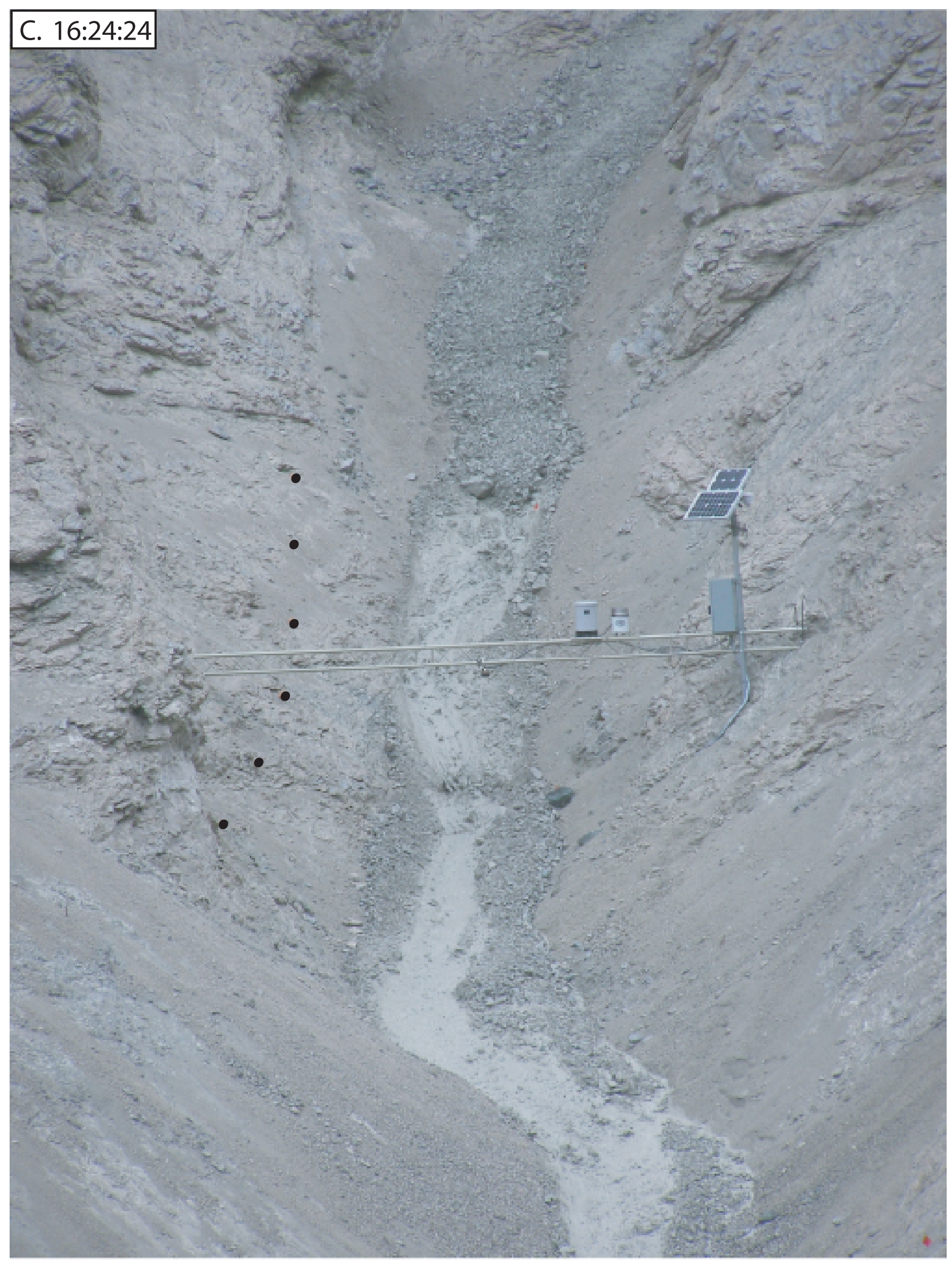




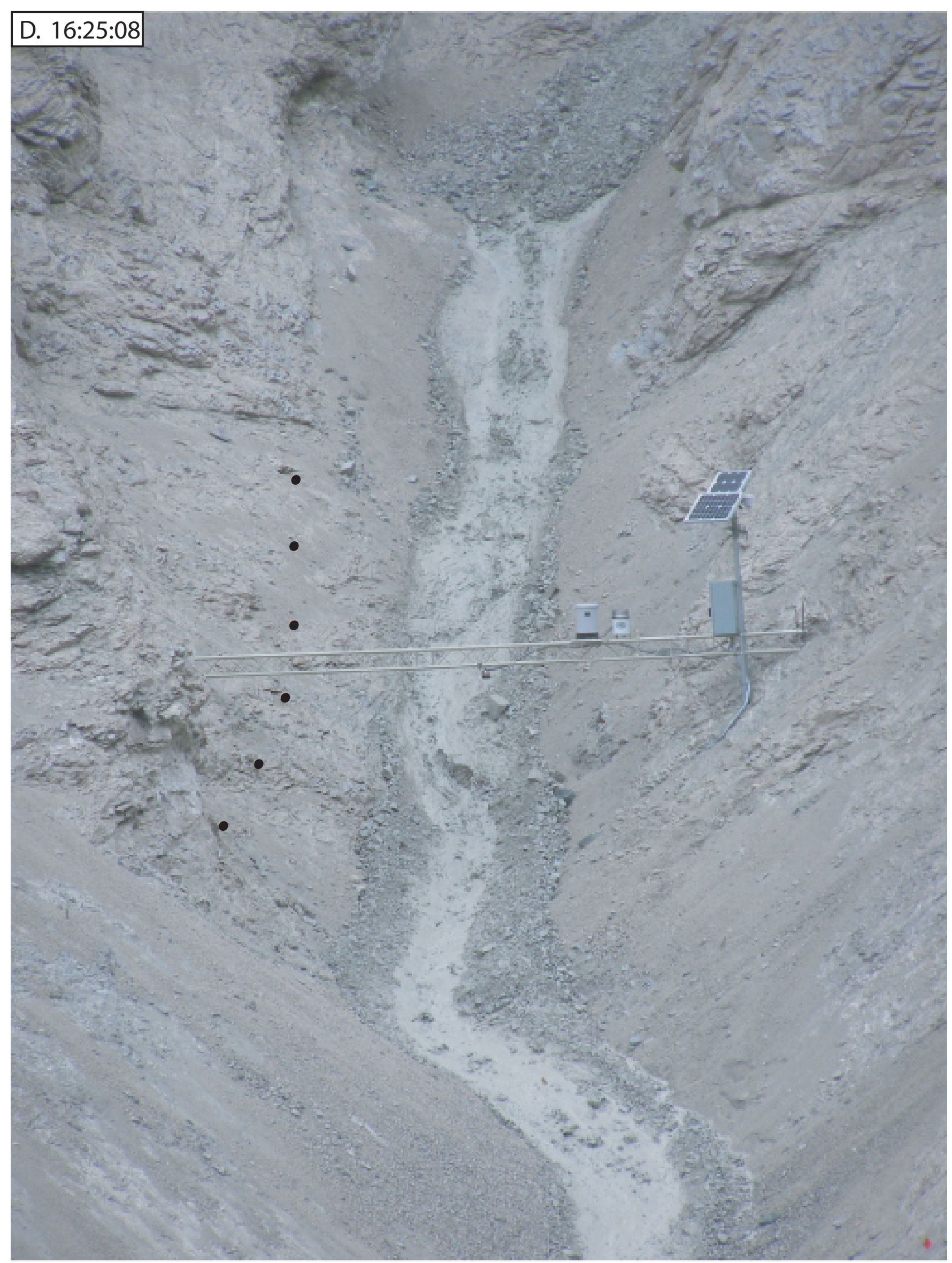



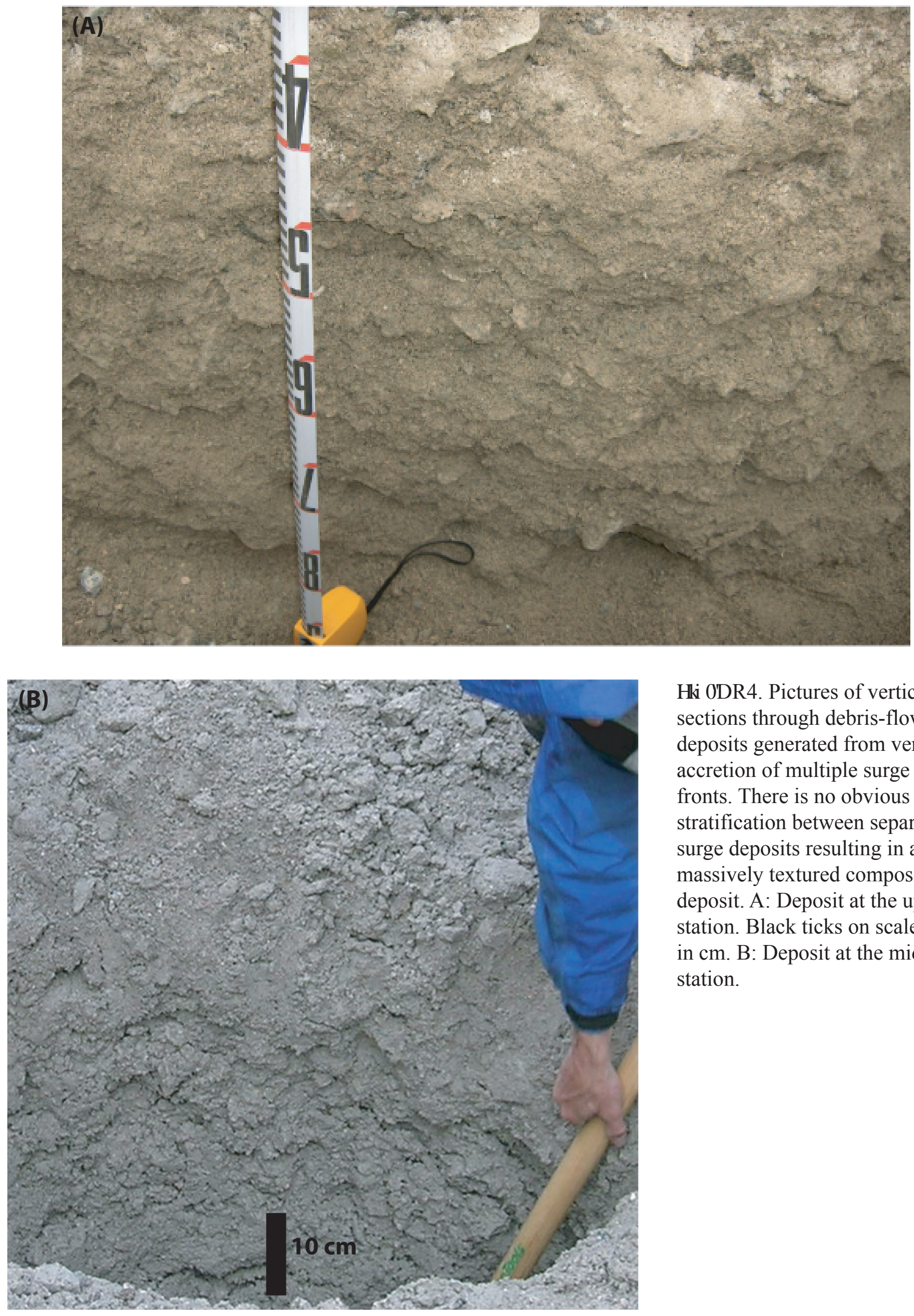

) IJUDR4. Pictures of vertical crosssections through debris-flow deposits generated from vertical accretion of multiple surge fronts. There is no obvious stratification between separate surge deposits resulting in a massively textured composite deposit. A: Deposit at the upper station. Black ticks on scale are in $\mathrm{cm}$. B: Deposit at the middle station. 
) IU⿴囗十 5. Wet bulk density time series. Wet bulk density time series $\rho(t)$ is calculated using $\rho(t)=\sigma(t) /(g H(t) \cos (\theta))$ where $\sigma(t)$ is the time series of total basal normal stress, $g$ is gravitational acceleration, $H(t)$ is the time series of stage and $\theta$ is the bed inclination. Red traces are smoothed $\rho(t)$ using a 3-point moving mean of the raw $\rho(t)$ plotted in black. Note much of the noise in the raw time series is due to differences in sampling rates of $\sigma(t)(250 \mathrm{~Hz})$ and $H(t)(0.5 \mathrm{~Hz}) .250 \mathrm{~Hz}$ $\sigma(t)$ data were down sampled to $10 \mathrm{~Hz}$ by binning data in $0.1 \mathrm{sec}$ bins and taking the mean of each bin. Then the $10 \mathrm{~Hz}$ data were interpolated to $0.5 \mathrm{~Hz}$ corresponding to the $H(t)$ time-series. A: Bed sediment and flow combined wet bulk density. B: Flow-only wet bulk density. To calculate flow-only bulk density both $\sigma(t)$ and $H(t)$ were set to zero at $16: 22,54$ seconds before the first surge arrived. Sediment was deposited during the passage of most surges (see C). As sediment accumulates the flow-only bulk densities again become an average of flowing material and recently deposited sediment, which makes it progressively more difficult to identify the shallow, lower density, water rich tail. C: Traces of $H(t)$ and $\sigma(t)$ reproduced from Fig. 2B.
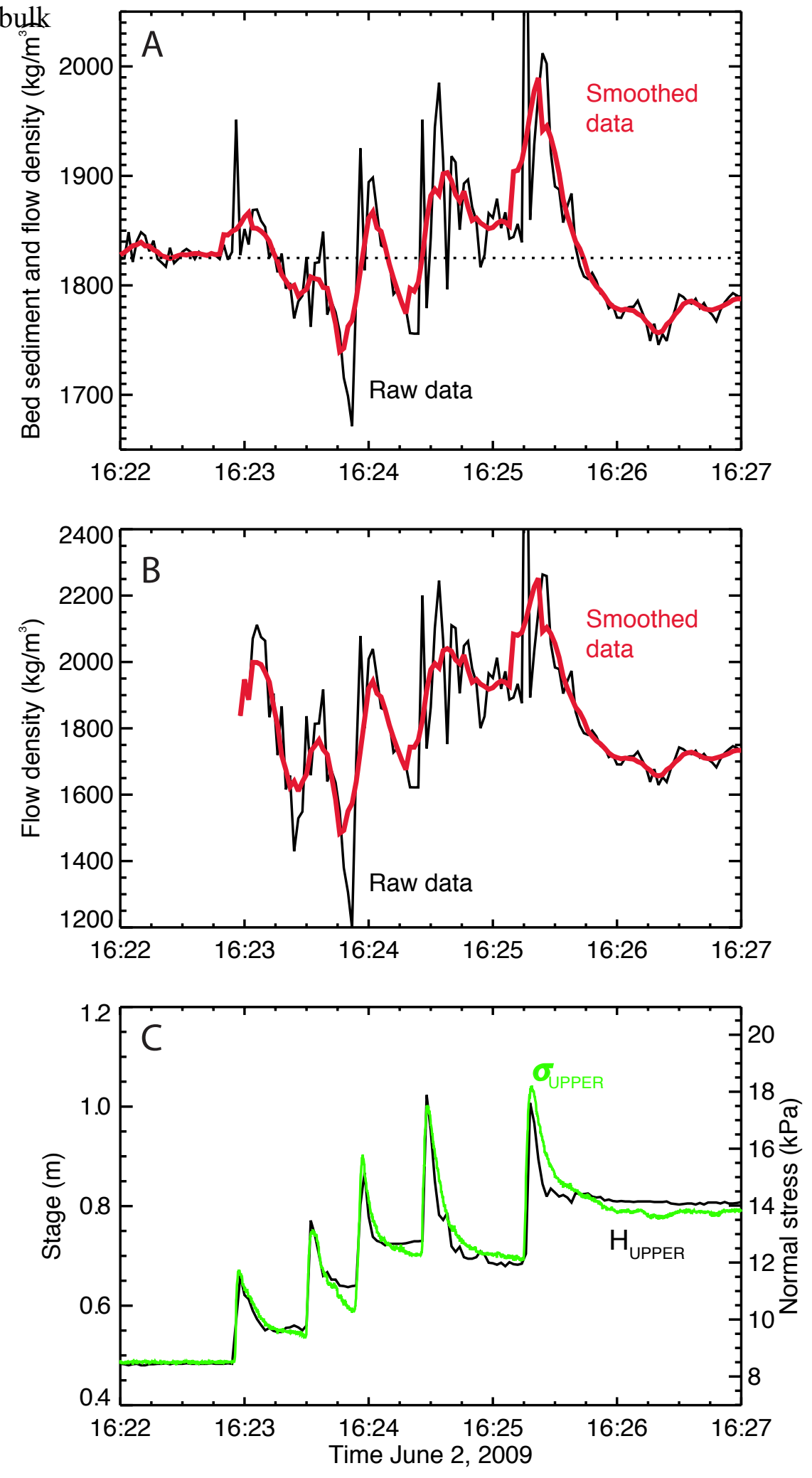